\title{
PROPIEDADES Y RENTAS DE LA ORDEN DE SANTIAGO EN ORIHUELA DURANTE LA BAJA EDAD MEDIA
}

\author{
Miguel RODRÍGUEZ LLOPIS \\ Universidad de Murcia
}

La implantación de la Orden de Santiago en Orihuela debe analizarse en el contexto general del asentamiento de los santiaguistas en el reino de Murcia, desde las alejadas encomiendas de Segura y Yeste en la cuenca alta del río Segura hasta las propiedades obtenidas en Murcia y Orihuela, que no llegaron a conformarse como señoríos. Además, el interés de la Orden por conseguir señoríos en este sector meridional de la cuenca del Segura se inicia en los años siguientes a la anexión del reino a Castilla y es fruto evidente de la ayuda militar prestada por los santiaguistas en el control del territorio y en la toma de algunas plazas rebeldes, como fue el caso de la misma Orihuela'.

En un principio, la Orden obtuvo algunos señoríos sobre la vega oriolana, que sólo pudo mantener durante unos años debido a la presión de la nobleza castellano-aragonesa. Así, en 1255, el monarca les concedía Callosa y Catral, aldea por entonces de Orihuela, que cambiaron dos años después por Aledo y Totana ${ }^{2}$. También conseguirían la posesión de Abanilla tras la revuelta mudéjar de 1264-1266, que tuvieron que

1 En 1256, Alfonso X concedía a don Pedro Fernández, comendador de Segura, como representante de la Orden de Santiago la aldea de Abeiazar en la Mancha, "por el serviçio que me fizo sobre Orivela quando la gane..." (Juan Torres Fontes (ed.), Fueros y privilegios de Alfonso $X$ el sabio al reino de Murcia, Academia Alfonso X, Murcia, 1973, pp. 36-38 (en adelante Codom III).

2 El 15 de junio de 1255 los santiaguistas recibían la villa y castillo de Callosa más la aldea oriolana de Catral a cambio de algunas de sus propiedades en el norte de Castilla. Las perdieron por canje con Aledo y Totana el 14 de abril de 1257 (Codom III, pp. 32-34 y 47-49). 
reintegrar al noble Ramón de Rocafull a cambio de Cieza33. Desaparecían, así, las posibilidades de la Orden de conseguir señoríos en la vega baja del Segura, limitándose desde entonces a crear y organizar un pequeño conjunto de propiedades urbanas y rurales en la ciudad y huerta de Orihuela que son el objeto de este trabajo.

\section{LAS DONACIONES DEL SIGLO XIII}

La activa participación de Pelay Pérez Correa, maestre de Santiago, en la reconquista del territorio murciano tras la sublevación mudéjar de 1264 tuvo como recompensa la donación real de numerosas propiedades a la Orden en las huertas de Murcia, Lorca y Orihuela, sin contar los señoríos que consiguieron en el reino a partir de entonces. En 1266, Alfonso X les concedía «en Orihuela las casas et todo el heredamiento que fue de Abez, assi como lo el auie e aun les damos el alcaria que dizen Alcorphe, que es termino de Orihuela, con todos sus heredamientos et con todas sus pertenencias, assi como las auie en tiempo de moros ${ }^{4}$. Desconocemos la extensión del llamado «heredamiento de Abez», que bien pudiera estar constituido por las heredades que la Orden aglutinó en torno a la acequia de Almoradí, además de algunas de las casas que poseerá en el casco urbano; por el contrario, sí ha llegado hasta hoy sin fraccionar la heredad de Algorfa por lo que podremos, más adelante, analizar su extensión y gestión.

En 1271, la Orden realizaba una concordia con el obispo y cabildo de la Iglesia de Cartagena para el reparto de los diezmos de estas propiedades, aceptando la Orden pagarles «... en Oriola et en su termino, la ochaua parte de todos los diezmos de menudo et de granado"; y se comprometían, además, a pagar con sus rentas de Murcia y Orihuela lo que valieran los diezmos de Moratalla, Orce y otros lugares mientras estuvieran poblados de musulmanes. A cambio los santiaguistas recibían la iglesia de Santiago de Orihuela con las dos terceras partes de sus diezmos 5 .

A fines del siglo XIII ya se encontraba conformado el patrimonio santiguista en Orihuela, aunque las dificultades por las que atravesaba el reino no permitían todavía realizar una gestión eficaz de estas propiedades. Así, al igual que ocurrió en otras ciudades donde la Orden tenía bienes, éstos se utilizaron para establecer convenios con particulares que los recibían en usufructo a cambio de nombrar a la Orden como heredera; y, así, en 1294 el maestre Juan Osorez concedía en usufructo vitalicio a Juan Muntaner y a su mujer Alamanda los bienes de la Orden en Orihuela y les otor-

3 Abanilla había sido concedida a Orihuela como aldea en 1266 (Codom III, pp. 89-91). El cambio por Cieza fue realizado el 24 de abril de 1281 (Codom III, pp. 158-160).

4 La donación se realizaba en Sevilla, el 21 de mayo de 1266 (Juan Torres Fontes (ed.), Documentos de Alfonso $X$ el Sabio, Academia Alfonso X, Murcia, 1963, pp. 26-28).

5 Esta avenencia se realizó en Murcia, el 27 de julio de 1271 y será anulada por el Pontifice en 1282 (Juan Torres Fontes (ed.), Documentos del siglo XIII, Academia Alfonso X, Murcia, 1969, pp. 3941 y $71-72$ ). 
gaba el hábito de Santiago; todo ello a cambio de las propiedades que este matrimonio poseía en Lorca ${ }^{6}$.

\section{LA CONQUISTA ARAGONESA Y LOS PROBLEMAS DE LA ORDEN DE SAN- TIAGO EN ORIHUELA}

La anexión de una parte del reino de Murcia a Aragón, realizada por Jaime II desde 1296, modificó sustancialmente la situación de la Orden de Santiago en Orihuela, ya que los comendadores santiaguistas y el mismo maestre de la Orden se mostraron partidarios del rey castellano desde el inicio de la contienda. Los bienes de Orihuela fueron confiscados por Jaime II y concedidos sucesivamente a varias familias afectas a la monarquía aragonesa, aunque al finalizar la contienda, en 1304, la familia Muntaner pudo mantener el usufructo que había acordado con la Orden varios años antes ${ }^{7}$. Desde la incorporación definitiva de Orihuela a la Corona de Aragón, las propiedades oriolanas de la Orden pasaron a depender de la encomienda mayor de Montalbán desvinculándose para siempre del resto de sus posesiones murcianas.

Durante la primera mitad del siglo XIV, la Orden apenas pudo disponer de su patrimonio oriolano. Las tensiones entre los reyes de Castilla y Aragón y diversos hechos fortuitos hicieron que sus propiedades estuvieran embargadas durante la mayor parte de aquel período. Los acontecimientos son suficientemente conocidos y están íntimamente relacionados con la villa murciana de Ceutí. Detallémoslos brevemente.

La villa de Ceutí había sido perdida por los santiaguistas durante la conquista aragonesa del reino murciano, de manera que, en 1298, sus nuevos señores la habian puesto en venta, siendo comprada por Ramón de Manresa, vecino de Barcelona ${ }^{8}$. Tras los tratados de Torrellas-Elche que fijaron las nuevas fronteras entre Aragón y Castilla, los santiaguistas pretendieron recuperar su antigua posesión y ocuparon Ceutí, con las subsiguientes protestas de Ramón de Manresa ante Jaime II. En 1308, el rey ara-

6 El convenio se firmaba en Baeza el 22 de abril de 1294 (AHN, Órdenes Militares, Uclés, carpeta 50 , vol. I, doc. 9).

7 En marzo de 1304, Jaime Il había intentado conceder la heredad de Algorfa a Ramón de Mula en compensación por los daños que le habían causado los comendadores de Aledo y Moratalla; esta donación no pudo llevarse a efecto por haber sido antes concedida a Ramón Muntaner, cuyos vínculos familiares con Juan Muntaner y Alamanda son muy imprecisos. En mayo del mismo año, Jaime II restituía esta heredad a Juan Muntaner (ACA, Cartas reales Jaime II, núm. 2322 y reg. 132, fol. 149. 149v).

8 El 30 de julio de 1298, Guillén Moncada, Bonamich Zavila y Jaime Serra, albaceas testamentarios de doña Dolza, viuda de Ramón Despuig, señora de Ceutí, ordenaron pregonar en Murcia la venta del citado lugar. Días atrás se había recibido una carta de Juan de Vidaure, procurador de don Jaime, señor de Xérica, instando a los albaceas a realizar la venta para pagar las deudas de doña Dolza. El mismo día treinta, estando presente, también, Berenguer de Juya, sobrino y heredero de doña Dolza, se vendió la villa —con torre y cortijo- a Ramón de Manresa por veinte mil sueldos «de reals de Murcia” (AHN, Ordenes Militares, Uclés, carp. 208, vol. II, doc. 2). 
gonés ordenaba indemnizarle con las rentas santiaguistas en $\operatorname{Aragón}^{9} \mathrm{y}$, años después, con las dificultades surgidas por los impagos, ordenaba concederle las propiedades oriolanas de la Orden en compensación por lo perdido. El problema fundamental continuó sin solucionarse porque los bienes santiaguistas en Orihuela rentaban mil doscientos sueldos anuales mientras que las rentas de Ceutí alcanzaban los tres mil cuatrocientos ochenta sueldos al año, por lo que la descompensación era evidente ${ }^{10}$.

El pleito entre la Orden y Ramón Manresa se mantuvo en los años siguientes ${ }^{11}$ hasta que, en 1332, la reina Leonor sentenció la devolución de Ceutí a Ramón de Manresa y la reintegración de sus posesiones oriolanas a los santiaguistas ${ }^{12}$. Aquel mismo año se realizó el intercambio de bienes y Alfonso IV de Aragón dio por concluido definitivamente el asunto $^{13}$. El problema estaba solucionado pero el estado de las posesiones santiaguistas en Orihuela dejaba mucho que desear y los difíciles años que siguieron dificultaron mucho más su puesta definitiva en explotación.

\section{LAS PROPIEDADES DE LA ORDEN DE SANTIAGO EN ORIHUELA DURANTE LOS SIGLOS XIV Y XV}

Solucionados los conflictos originados por la conquista aragonesa, la Orden recuperó la propiedad de Algorfa, de varias parcelas de regadío en la huerta de Orihuela y de un conjunto de inmuebles urbanos en la ciudad. No obstante, en el transcurso de los conflictos vividos, se perdió la propiedad de algunas tierras y casas que no pudieron ser ya recuperadas. Parece, incluso,que Redován, otra gran heredad oriolana, le había pertenecido, lo que explicaría la ausencia de noticias que existe sobre ella en los sucesivos repartimientos del siglo XIII'14. El 6 de abril de 1495, los visitadores

9 El 11 de mayo de 1308, Jaime II ordenaba al baile de Orihuela, que certificara qué bienes poseía la Orden en la ciudad porque deseaba darlos a Ferrer de Manresa encompensación de Ceutí (Regina Sainz de la Maza Lasoli, La Orden de Santiago en la Corona de Aragón. La encomienda Mayor de Montalbán (1210-1327), Zaragoza, 1980, apéndice documental núms. 169 y 170).

10 El 5 de febrero de 1321, Jaime II ordena al comendador de Montalbán que devuelva Ceutí a Ferrer de Manresa o que lo supla con otros bienes. El 9 de octubre se le entregaban Algorfa y ciertas rentas de Fradell como compensación ( $R$. Sainz de la Maza, o.c., docs. núms. 213 y 215).

11 El 18 de julio de 1328, Arnalt Masquefa, procurador del comendador don Vidal de Vilanova, compareció ante el concejo de Murcia para solicitar ciertos traslados de la compra de Ceutí de 1298, presentando una carta de Alfonso III solicitando que le ayudasen. En julio de 1332, el rey aragonés concedía plazo a Ferrer de Manresa para presentar procuradores (AHN, Órdenes Militares, Uclés, carp. 208, vol. II, n. 2 y 4).

12 AHN, Órdenes Militares, Uclés carp. 208, vol. II, n. 4.

13 1332-agosto-22. Valencia. - Carta de don Vidal de Vilanova a Pedtro Lopez Fajardo, alcaide de Ceutí, comunicando que Ferrer de Manresa, ciudadano de Barcelona iba devolver los lugares de Fradell y Algorfa y lo que la Orden tenia en Orihuela si le restituian Ceuti. y ordenándole que lo devuelva. (AHN, Órdenes Militares, Uclés, carp. 208-II, nº y Bullarium, pp. 302-303). El 8 de septiembre de 1332 se realizó la entrega. y el 27 de octubre Alfonso IV declaraba que Algorfa pertenecía a la Orden (AHN, Órdenes Militares, Uclés, carp. 208-II, no 5 y Bullarium, pp. 301-302).

14 Así lo señala Juan Torres Fontes, Repartimiento.., p. LXXVI. 
santiaguistas "...ovieron informaçion en commo Redovan haze çenso a la dicha Horden e a la encomienda de Montaluan çinquenta tynbres, fadiga e luismo, el qual dicho Redovan posee agora mosen Santangelo, bayle de Orihuela». Fue demasiado tarde para poder recuperarla ${ }^{15}$.

La gestión de todas las posesiones se realizó desde la encomienda mayor de Montalbán, cuyos comendadores percibieron los censos correspondientes. En una fecha indeterminada del siglo $\mathrm{XV}$, posiblemente coincidente con el nombramiento de miembros del linaje Hijar como comendadores de Enguera, la percepción de los censos pasó a depender de esta otra encomienda.

\subsection{La heredad de Algorfa}

Fue concedida a la Orden en 1266 y estaba situada junto al río Segura tras su paso por Orihuela. Su extensión superficial alcanzaba las cinco mil tahúllas, aunque la mayor parte de ellas eran tierras improductivas y montes con matorral. Su núcleo esencial lo constituían las parcelas de regadío situadas junto al río, unas cuatrocientas tahúllas en el siglo XIII que fueron ampliadas hasta quinientas a principios del siglo XVI ${ }^{16}$. Menos conocida es la extensión de la superficie no cultivada, ya que los límites actuales del término de Algorfa son algo mayores que los documentados en la Edad Media ${ }^{17}$.

Como se destacó anteriormente, la heredad pasó por situaciones adversas durante la primera mitad del siglo XIV, siendo recuperada por la Orden en 1332. Integrada, por entonces, en la encomienda mayor de Montalbán, no pudo ponerse en explotación hasta la década de 1380, debido a los negativos efectos que las pestes de mediados de siglo y la guerra castellano-aragonesa tuvieron sobre la huerta oriolana. En 1354 , los santiaguistas se quejaban ante el concejo de Orihuela de los pechos que se les habían repartido y de la sobretasación que habían realizado del conjunto de sus propiedades, escasamente rentables por entonces ${ }^{18}$. Además, por aquellos años, la

$15 \mathrm{AHN}$, Órdenes Militares, Manuscritos Santiago 1114C, p. 13. Habia sido comprada por Jaume Santángel en 1490 (J.B. Vilar Ramirez, Los siglos XIV y XV en Orihuela, Patronato Ángel García Rogel, Murcia, 1977, p. 150).

16 En la segunda partición de la huerta oriolana, en 1268, se afirma "En la quadrella de Mathet es la meatat d'Algezira, a tenente desta alcarea es Algorfa, de la Horden de Ucles, en que non partieron nada", para añadir más adelante "En Algorfa, de la Orden d'Ucles, ha CCCC at." (Juan Torres Fontes, Repartimiento de Orihuela, Academia Alfonso X-Patronato Ángel Garcia Rogel, Murcia, 1988, p. 3). En la visita de 1509 se le atribuyen 480 tahúllas de riego y en un cabreo realizado en 1531 se sitúan en 500 (AHN, Órdenes Militares, Manuscritos Santiago 1118C, pp. 22-25 y Uclés, carp. 115, no 13 ).

17 Alcanza en la actualidad las ocho mil... (Juan Torres Fontes, Repartimiento..., pp. LXXIV-LXXV). Los límites de Algorfa estaban definidos por el río Segura, el camino que va a Guardamar, y la sierra.

18 El 6 de septiembre de 1354 Juan de Uceda, procurador del comendador de Montalbán, com. parecía ante el consell para recordar que los bienes de la Orden estaban exentos del pago de la talla, y que, además, no valían más de 15.000 florines, mientras que se les habían tasado en 30.000 y obligado a pagar como si valieran 90.000 florines (AMO, libro 1, fol. 54). 
principal partida de ingresos de los santiaguistas en Orihuela procedía del arrendamiento de los herbajes de la heredad de Algorfa, que realizaba el comendador mayor de Montalbán con cierta oposición del concejo oriolano que entendía que las hierbas de Algorfa debieran integrarse en los arrendamientos del conjunto de la huerta, por ser una propiedad más y no un señorío. En este sentido, en 1383, los pastos de Algorfa habian sido arrendados a Pere Pastor, vecino de Valencia, por 22 florines de oro, cifra que proporciona una idea de las dificultades existentes todavía para conseguir una explotación idónea del territorio ${ }^{19}$.

La situación comenzaba, sin embargo, a mejorar y, en diciembre de aquel mismo año de 1383, don Pedro Fernández de Hijar, comendador mayor de Montalbán, intentaba poblar la heredad con labradores oriolanos a los que les ofrecía adquirir tres pares de bueyes en Villajoyosa, población santiaguista, a pagar en cinco años, siempre que se comprometieran a trabajar en la heredad durante ese período. Les permitía, también, techar las casas ruinosas allí existentes y prometía reparar la torre otro año "si Deus lo uol». Simultáneamente, ordenaba abrir información sobre el estado y poseedores de otras propiedades de la Orden en Orihuela para arrendarlas de nuevo. No debía de ser, sin embargo, excesivamente optimista sobre el triunfo de esta repoblación porque recomendaba, como alternativa, arrendar la heredad completa si alguien la quisiera por cinco o seis años ${ }^{20}$. Así se haría, finalmente, ya que en 1394 «por razon que se hallaua mas dinero a çenso perpetuo que a rendaçion", la heredad fue concedida en enfiteusis, aunque desconocemos la identidad del censalero ${ }^{21}$. Se mantuvo bajo este régimen de explotación durante el resto del período estudiado.

La cesión del dominio directo en enfuteusis permitió la puesta en explotación de toda la heredad y su continua mejora en los rendimientos a juzgar por las sucesivas descripciones que se han conservado de ella. Mientras tanto, el censo pagado a la Orden quedó inmovilizado desde las últimas décadas del siglo XIV en 615 sueldos. La localización de la heredad junto al Segura permitió mantener un núcleo de cuatrocientas a quinientas tahúllas de regadío en torno a la acequia de Alquibla, además de una superficie de secanos en los que existía un olivar, algarrobos y otros arboles, con algunas viñas. Más allá de estos secanos se extendían una gran superficie de montes

19 Esta información la proporcionaba Jaime de Aliaga, procurador del comendador de Montalbán, al concejo de Orihuela (AMO, Libro 5 , fols. 59v-61).

20 Existía en la heredad, todavía, un olivar que se adjudicaría al primer poblador con la obligación de labrarlo. También se recuerda que la persona encargada por la Orden de recoger los censos debe de percibir el diezmo de todas las heredades "car axi y es la costum del regne" (AMO, libro 5 , fols. 59-61).

21 El contrato enfitéutico se firmó en Orihuela el 3 de marzo de 1394, por orden de don Pedro Fernández de Híjar, comendador mayor de Montalbán, y con consentimiento de fray Alonso Herrández, soprior de la iglesia de Santa María del Castillo de Montalbán, y de don Pedro de Ovon, caballero santiaguista, que dieron poder a Juan Pérez del Castellar, comendador de Enguera, y a Juan Jiménez de Bolas, escudero de Belchit, para realizar el contrato (AHN, Órdenes Militares, Manuscritos Santiago $1117 \mathrm{C}, \mathrm{pp} .13-15)$. 
con algunos pastos de invierno. Junto al regadío, existía un núcleo edificado compuesto por una torre con dependencias anexas entre las que se documenta un molino de aceite, un lagar y corrales ${ }^{22}$.

Además, desde 1484, la heredad estuvo en posesión de la familia Masquefa, cuyos miembros desarrollaron un hábil programa de compras, enajenaciones y usurpaciones para ampliarla y unirla con el pago de Matet, que era una rica propiedad familiar limítrofe con ella. Por esta razón, el concejo oriolano escribía, en 1484, a don Fernando de Híjar, comendador de Enguera, quejándose de los intentos de don Pedro Masquefa para anexionarse una legua de términos realengos y de los impedimentos que ponía a los vecinos de la ciudad para realizar aprovechamientos comunales en los montes de la heredad ${ }^{23}$. Estos intentos de ampliar y definir más generosamente los límites de Algorfa propiciaron la aparición de conflictos puntuales con algunos vecinos de Orihuela cuyas propiedades quedaron dentro de la heredad santiaguista; si, en 1499, los visitadores adjudicaron para la Orden una casa edificada por Pedro Fernández de Tuesta dentro de la heredad ${ }^{24}$, años después, Enrique Masquefa compraba doce tahúllas de regadío que se encontraban junto a la alquería y cuya situación le resultaba bastante incómoda para la gestión global de la finca ${ }^{25}$. La apropiación de tierras comunales por parte de los Masquefa había sido tan evidente que, aún en 1509, algunos vecinos oriolanos cultivaban tierras dentro de Algorfa, pretendiendo los Masquefa desalojarlos con mandamientos de los visitadores ${ }^{26}$.

22 La descripción más completa es la realizada en la visita de 1504: «... visitaron despues los dichos señores visitadores la dicha torre e alqueria e heredamiento y hallaron en la casa baxa vna entrada y establo con vna chimenea a mano derecha y dentro vn molino de azeyte con su rueda $y$ arnal y su viga lagar con su husyllo y pesa y vna camarita dentro del molino y debaxo della vn establito, mandaron los dichos vysitadores reparar en la dicha casa las cubiertas de la camarilla e mas que hagan todas las tapias que hallaron caydas del corral de la dicha casa baxa. E mas visitaron la torre e casa altas e hallaron la vna dellas bien reparada, saluo vna casa que estaua dentro en el corral que esta hazia Orihuela hallaron cayda la cubierta e derribadas algunas tapias del dicho corral, mandaron so pena de comiso cobrir la dicha casa e hazer las tapias de la torre e casas altas e todo lo suso dicho de la casa baxa fasta el mes de henero primero veniente del año de quinientos e çinco. No estaua el dicho Enrrique Mazquefa presente, fue mandado a mosen Pere de Fontes, procurador del dicho comendador de Enguera, lo notificase al dicho Enrrique Mazquefa. E mas visitaron la heredad suso dicha e hallaronla bien labrada, senbrada y plantada de muchas oliueras y garraferas y otros diuersos arboles e algunas viñas". (AHN, Órdenes Militares, Manuscritos Santiago 1117C, p. 15).

23 La carta está fechada el 6 de diciembre y detalla, además, las roturaciones que realizaba en montes públicos, la invasión de cañadas y caminos reales y la veda de la tala en lugares donde siempre se hicieron (AMO, libro 33, fols. 30-31v).

$24 \mathrm{AHN}$, Órdenes Militares, Manuscritos Santiago 1115C, pp. 23-24.

25 La compra se realizó entre 1504 y 1509. Enrique Masquefa las compró a Antoni Pérez con dineros propios; las cambió a la Orden por otras seis tahúllas de Algorfa que limitaban con su heredad de Matet, a la que las incorporó. Compró cada tahúlla a dieciocho libras y media (AHN, Órdenes Militares, Manuscritos Santiago 1118C, pp. 22-25).

26 Algorfa es vendida por Enrique Masquefa a Nuño Ferrández poco antes de 1509 en una extraña operación financiera que bien pudiera pretender evitar algún tipo de embargo, ya que es recuperada de nuevo por los Masquefa, documentándose en su poder en 1531. 


\subsection{Otras propiedades agrícolas}

El resto de las fincas agrícolas santiaguistas forman dos conjuntos compactos muy próximos a la heredad de Algorfa. Junto a la aldea de Benejúcer se localizan un total de ochenta y tres tahúllas, y algo más de sesenta en Almoradí. Se encuentran concedidas a censo a un grupo muy variado de enfiteutas en el que están representados desde miembros de la nobleza oriolana y del clero de la ciudad hasta simples campesinos. Sin embargo, desde los años finales del siglo XV, se aprecia un leve pero progresivo proceso de concentración de estas propiedades en algunas familias del patriciado local; un proceso en el que participan de manera activa algunos notarios que suministran información sobre las compraventas e, incluso, adquieren para sí algunas parcelas.

Algunas de estas parcelas se encuentran muy próximas al río Segura y están cercadas por tapias formando pequeños huertos; por ello, son las crecidas péríodicas del río uno de los principales problemas para los enfiteutas, que deben de afrontar los gastos de reparación de tapias y arbolado ${ }^{27}$. Por lo demás, son tierras dedicadas al cultivo del cereal con algunas líneas de moreras en los límites, aunque también existen parcelas dedicadas de forma exclusiva al cultivo de naranjos con algún otro frutal intercalado con ellos.

Si en las visitas de 1495 y 1499 todavía se aprecia la permanencia de estas parcelas en poder de algunas familias de campesinos locales, en el cabreo realizado en 1531 existe una progresiva introducción de nobles entre los enfiteutas de la Orden. Así, las mejores parcelas de Benejúcer habían sido adquiridas por «lo magnifich» Luis Martí, que también se apropiaba de ocho tahúllas en Almoradí; otras diez tahúllas en Benejúcer habian pasado a poder del también «magnifich» Juan Sanz, mientras que los nobles Lope Fernández de Mesa y Martin Alcaraz habían adquirido otras parcelas de Almoradí. Por último, los Masquefa, cuyos intereses en Algorfa ya analizamos, se documentan, también como enfiteutas, siendo titulado "lo magnifich" Juan Masquefa como "señor dels molins de la ciutat de Oriola"28.

Por lo general, no se aprecia entre las propiedades santiaguistas un acentuado proceso de fragmentación parcelaria motivado por herencias y particiones sucesivas de las fincas. Al contrario, se documenta un desembarco del patriciado oriolano que monopoliza progresivamente su posesión, en un proceso que parece simultáneo con lo que ocurre en otros sectores productivos de la ciudad ${ }^{29}$.

27 En 1504, se hallaban caidas las tapias del huerto y palomar que la Orden tenía en Almoradí, que lo poseía el presbitero mosen Alfonso Cristobal. Aquel año, el enfiteuta ya estaba construyendo los cimientos para levantar las tapias, pero, en 1509, todo se encontraba, de nuevo, destruido por otra avenida (AHN, Órdenes Militares, Manuscritos Santiago 1117C, p. 18 y 1118C, p. 27).

28 AHN, Órdenes Militares, Uclés, carp. 115, $\mathrm{n}^{\circ} 13$.

29 A falta de más estudios sobre estos temas, J.A. Barrio Barrio, El ejercicio del poder en un municipio medieval: Orihuela 1308-1479, Univ. Alicante, 1993, microficha. 
CUADRO № 1

PROPIEDADES RÚSTICAS DE LA ORDEN DE SANTIAGO EN LA HUERTA DE ORIHUELA (AÑO 1499)

\begin{tabular}{|c|c|c|c|c|}
\hline SITUACIÓN & EXTENSIÓN (tahúllas) & CENSATARIO & CENSO (en sueldos) & OBSERVACIONES \\
\hline Algorfa & 500 & Gaspar Masquefa & 615 & con más de tres mil tahúllas de baldios \\
\hline Benejúcer & 50 & Perote Martin & 41 & Con un solar de casa \\
\hline Benejúcer & 3 & Perote Martin & 3 & \\
\hline Benejúcer & 20 & Perote Sánchez & 20 & Con una casa-corral \\
\hline Benejúcer & 10 & Juan Sánchez & 7 y 6 dros. & Con dos eras \\
\hline Almoradí & 1 & Francisco Abret & 6 & \\
\hline Almoradi & $2^{\prime} 5$ & Francisco Abret & 125 & \\
\hline Almoradí & $2 \cdot 5$ & Francisco Abret & $12^{\prime} 5$ & \\
\hline Almoradí & 3 & Hijas de Pedro López & 15 s. y 7 dros. & \\
\hline Almoradí & 3 & Luis Esquer & 15 & Sembrada de trigo con moreras \\
\hline Almoradí & 4 & Mosén Alfonso Cristobal & 20 & \\
\hline Almoradí & Un huerto & Mosén Alfonso Cristobal & 12 & Con un palomar \\
\hline Almoradí & 4 & Lorenzo Menargues & 20 & \\
\hline Almoradí & 5 & Andrés Terrinches & 25 & \\
\hline Almoradí & $7 ' 5$ y media cuarta & Juan Ramon & 34 y 7 dros. & Plantada de naranjos \\
\hline Almoradí & 8 & Ferrán Martinez & 41 y 3 dros. & \\
\hline Almoradí & 8 & Frances Pérez & 41 y 3 dros. & Plantada de moreras \\
\hline Almoradí & 10 & Isabel Canosa & 47 y 7 dros. y meaja & Con una balsa de cocer lino y cáñamo \\
\hline
\end{tabular}

Fuente: AHN, Órdenes Militares, Manuscritos Santiago 1115C, pp. 9-24. 


\subsection{Las propiedades urbanas}

El grupo principal de edificios que son propiedad de la Orden se localizan en la parroquia de San Salvador; un conjunto de seis casas que se encuentran concedidas en enfiteusis a vecinos de la ciudad. Son, por lo general, contratos de censo antiguos, aunque la mayoría de ellas cambian sucesivamente de poseedor por medio de compraventas. En los años finales del siglo XV se encuentran en poder de algunos miembros de la nobleza oriolana (el caballero Jaime Martínez, familiar del obispo de Tarazona) y de algunos linajes empobrecidos, dándose en estos casos situaciones muy variadas; desde la fusión de varias viviendas en una sola hasta la ruina pogresiva de aquellas habitadas por enfiteutas sin medio económicos.

Por lo general, su estructura interna presenta elementos comunes y característicos de la arquitectura de la comarca ${ }^{30}$ : un patio interior, con pozo, al que se accede directamente desde las puertas principales de la vivienda; desde el patio se tiene acceso a varias dependencias domésticas: una cocina, un corral y alguna habitación para usos diversos; en la planta superior se encuentran los dormitorios y terrados que se integran, también, en la vida doméstica diaria al utilizarse como zonas de paso entre habitaciones e, incluso, entre viviendas ${ }^{31}$.

30 Existen breves descripciones de algunas de ellas: “...estaua byen reparada y tenia vna buena portada con sus puertas, entrando a la mano derecha esta vn palaçio e a la mano yzquierda tras la puerta vn pozo e mas adelante vna cozina frontero de la puerta prinçipal y esta otro apartamiento $y$ mandase por el vn corral con su puerta...»; o, también, «...hallaron que tenia vna buena portada entrando a la mano izquierda esta vna cozina con su chimenea y arriba avia vna camara con su retraymiento y baxo a la mano yzquierda estaua vn pozo y vn trascorral..." (AHN, Órdenes Militares, Manuscritos Santiago $1117 \mathrm{C}$, pp. 15 y 22).

31 En este sentido, las costumbres de los visitadores de la Orden chocan continuamente con las tradiciones locales. En varias visitas se obliga a los enfiteutas a reparar los terrados con mortero de cal y arena, mientras que los oriolanos tenian por costumbre solarlos con matjana. Así se constata en la visita de 1509 a dos de estas viviendas: "...segun parece por el libro de la visitacion pasada se hauia hecho mandamiento que se hechase solar de mortero en vn terrado que tiene la dicha casa menor questa encima de la puerta y hallaron que no estaua hecho y por quanto vuieron informacion que en aquel terrado trastauan e andauan mucho por encima del y que no hera bien ser de cal y arena porque se perdia luego y que era mejor ser hecho de matjana e visto que el suelo estaua hecho de matjana y que era mejor segun que todos dezian mandaron que estuviese asis; $y$, en otra de ellas «... vieron los dichos señores por vista de hojos no hauer necesidad de subir las dichas paredes, antes ser inconueniente porque por alli se mandan los otros terrados de la dicha casa y el solar no ser necesario de hazerse de mortero antes ser mejor hazerse de matjiana porque es necesario andar por el terrado y lo tienen por mejor en esta tierra» (AHN, Órdenes Militares, Manuscritos Santiago 1118C, pp. 21-22). 
CUADRO № 2

PROPIEDADES URBANAS DE LA ORDEN DE SANTIAGO EN ORIHUELA

(AÑO 1499)

\begin{tabular}{|lllll|}
\hline SITUACIÓN & TIPOLOGía & CENSATARIO & $\begin{array}{c}\text { CENSO } \\
\text { (en sueldos) }\end{array}$ & OBSERVACIONES \\
\hline Junto al río & Molino harinero & Juan y Francesc Soler & 200 & 1/3 del molino es de Juan Soler y $2 / 3$ de Francisco \\
\hline San Salvador & Casa & Mujer de Rafael Oronel & 20 & \\
\hline San Salvador & Casa & Isabel Tora & 16 & Convertida en corral \\
\hline San Salvador & Casa & Jaime Martinez & 20 & \\
\hline San Salvador & Casa & Hijo de Alonso Ballester & 10 & \\
\hline San Salvador & Casa & Jaimot Martinez & 30 & \\
\hline San Salvador & Casa & Jaimot Martimez & 10 & Incorporada a la anterior \\
\hline
\end{tabular}

Fuente: AHN, Órdenes Militares, Manuscritos Santiago 1115C, pp. 9-24.

Fuera de la ciudad, la Orden posee un molino harinero, localizado junto al río Segura. Estaba formado por cuatro ruedas, tres de ellas en continuo funcionamiento y la cuarta sólo utilizada cuando el caudal de la acequia era suficiente ${ }^{32}$. Mantenía, además, una tahulla de tierra junto a él que, en 1504, se encontraba plantada de moreras. La Orden habia concedido el molino en enfiteusis en 1336 y, desde entonces había percibido doscientos sueldos de censo ${ }^{33}$. En los años finales del siglo XV se encuentra en posesión de la familia Soler, caballeros de Orihuela, cuyos ascendientes lo habian adquirido por compra en torno a $1355^{34}$.

\section{LA PRESENCIA SANTIAGUISTA EN ORIHUELA}

No existió en Orihuela presencia alguna de miembros de la Orden, al menos en las décadas finales de la Edad Media, al contrario de lo ocurrido en otras poblaciones de realengo en donde era frecuente la existencia de caballeros y freires santiaguistas que, por lo general, cuidaban de los intereses de la Orden en el territorio, percibían las

32 «...que le venia poca agua, para moler cosas de menudençias fuera de trigo" (AHN, Órdenes Militares, Manuscritos Santiago 115C, pp. 10-12).

33 Don Vidal de Vilanova, comendador mayor de Montalbán, dió poder a Bartolomé Dodena, baile de Villajoyosa, para acensar los bienes de la Orden. El molino fue acensado el 9 de noviembre de 1336 por doscientos sueldos, siendo valorado en cien libras (AHN, Órdenes Militares, Manuscritos Santiago 1117C, pp. 11-13).

34 Así lo afirman Juan y Francisco Soler, hermanos, durante la visita de 1499. En 1504, lo poseia mosen Diego Soler. En 1531, se encuentra en poder de mosen Diego Soler, caballero, y de Juana Soler, viuda del "magnifich» Cristobal Martí; Diego Soler poseía dos terceras partes del molino (AHN, Órdenes Militares, Uclés, carp. 115, nº 13). 
rentas existentes en la ciudad o residían en las casas de la Orden. Durante las diversas visitas realizadas a Orihuela desde 1495 a 1509, sólo se constata la residencia en la ciudad de mosen Jaime Montiel, un curioso freire santiaguista que había residido en el convento de Uclés y que niega, continuamente, su pertenencia a la Orden, llegando a exhibir un breve apostólico que le declara como miembro de la Orden de San Pedro y le excusa de obediencia hacia los santiaguistas ${ }^{35}$.

La representación de la Orden en la ciudad para la percepción de los censos la ostentaban alguno de sus vecinos. Entre 1495 y 1504, fueron el notario Nicolás Oller y mosen Pere Fontes los encargados de los asuntos santiaguistas en Orihuela, siendo este último el procurador del comendador de Enguera ante los sucesivos visitadores que llegaron a la población ${ }^{36}$. No parece, sin embargo, que las rentas censales fueran asignadas a estos personajes, que se documentan como meros intermediarios entre los comendadores de Enguera con los enfiteutas y con los visitadores santiaguistas.

Por otra parte, el valor global de las rentas santiaguistas apenas experimentó variaciones en todo el período analizado, por estar constituidas todas ellas por contratos de enfiteusis no renovables. Los 1.182 sueldos que se percibían por ellas en 1468 aumentaron hasta aproximarse a los mil trescientos a finales del siglo XV, cuando la Orden pudo ejercer un mayor control de la totalidad de sus propiedades. Por lo demás, las pequeñas alteraciones que se constatan en las cuentas ofrecidas por el procurador a los visitadores se deben al desconocimiento inmediato que se tenia sobre la extensión exacta de algunas parcelas y sobre el monto concreto de algunos censos que, por ser muy antiguos, eran modificados levemente por sus poseedores ${ }^{37}$.

35 En 1495, declaran los visitadores que lo “... hallaron syn el abito y ensynia de la dicha Horden e commo los otros freyres della anda en la yglesya colegial de la dicha çibdad revestido e colocado en la Orden de San Pedro y canonigo de la dicha yglesya" (AHN, Órdenes Militares, Manuscritos Santiago $1114 \mathrm{C}$, p. 12).

36 En 1509, es Antonio de Fontes el procurador del comendador de Enguera.

37 Las cifras correspondientes a 1468 han sido publicadas por A. Franco Silva, "Rentas y vasallos de las Órdenes Militares de Santiago y Calatrava en la corona de Aragón durante el siglo XV", Anuario de Estudios Medievales, vol. 18 (Barcelona, 1988) p. 518. 